\title{
Thyroid Invasion in Advanced Laryngeal Cancers: About 59 Cases at the ENT Departments in Academics Hospitals of Dakar from 2007 To 2011
}

\author{
Diom ES $S^{1}$, Abi $\mathrm{H}^{1}$, Ndiaye $\mathrm{C}^{1 *}$, Diallo $\mathrm{BK}^{2}$, Tall $\mathrm{A}^{1}$, Ndiaye $\mathrm{M}^{1}$, Ndiaye $\mathrm{IC}^{1}$, Diouf $\mathrm{R}^{2}$ and Diop EM ${ }^{1}$ \\ ${ }^{1}$ Department of Otolaryngology, UCAD/ FANN Hospital, Senegal \\ ${ }^{2}$ Department of Otolaryngology, Albert Royer Hospital/ UCAD, Senegal \\ ${ }^{3}$ Department of Otolaryngology, UCAD/ HOGGY Hospital, Senegal
}

*Corresponding author: Ciré Ndaiye, Department of Otolaryngology, UCAD/ FANN Hospital, Senegal

\begin{abstract}
Objectives: Description of epidemiology, clinical features and survival of patients undergoing laryngectomy and thyroidectomy for larynx carcinoma extending to the thyroid gland.

Patients and Methods: This study concerned adult patients from ENT departments in Academic Hospitals (Aristide Le Dantec and Fann) who had a total laryngectomy and a thyroidectomy.

Results: Fifty-nine (59) patients had total laryngectomy (TL) with thyroidectomy. The average age was 52 years. There were 58 men (98.3\%) and one woman (1,7\%). Laryngeal tumors (TNM classification) were very advanced (T3-T4) in 58 patients (98.3\%). The TL was combined with a thyroidectomy in all cases. Four patients $(12.5 \%)$ had invasion of the thyroid gland by the squamous carcinoma originating from the larynx. Survival was $10 \%$ at 5 years. There was no significant difference according to thyroid gland invasion or not $(\mathrm{p}=0.15)$.

Conclusion: This poor prognosis is certainly related to the fact that patients attend late but also is related to the deficits of the technical platform
\end{abstract}

Keywords: Laryngectomy; thyroid spread; prevalence

\section{Introduction}

Pharyngo-laryngeal cancers can invade the thyroid gland. In the literature the prevalence of this invasion is between 1 and $23 \%$ after a histologic examination of the total laryngectomy parts (TL) or pharyngolaryngectomy (PLT). The existence of anatomical areas of weakness (cricothyroid membrane) and of resistance (laryngeal cartilages) explains the extension of these cancers to the thyroid [1]. According to prevalence figures, a total thyroidectomy (TT) or a hemi-thyroidectomy (LIT) is done unnecessarily in more than $75 \%$ of TL or PLT. In Senegal, several studies [2-9] have been published relating to the larynx and thyroid disease since the first TL performed in 1980 by EM Diop. In this study, we describe epidemiological and clinical aspects of patients undergoing laryngectomy and a thyroidectomy for squamous carcinoma of the larynx extending to the thyroid gland and evaluated their survival.

\section{Material and Methods}

\section{Methods}

We undertook a retrospective study over 5 years (January 2007 to December 2011) at the ENT department Academics Health Centers Aristide le Dantec (HALD) and FANN in Dakar and at the Anatomy-pathology laboratories of the HALD and of the FMPOS at UCAD. Fifty-nine (59) patients underwent total laryngectomy (TL), a neck dissection and total thyroidectomy (TT), LT with subtotal thyroidectomy (subtotal) or ipsilateral hemi-thyroidectomy. The histological examination of the surgical specimen TL specimen included the lymph nodes and thyroid gland. Some patients had received radiotherapy and hormonal replacement therapy. Computer software ACCESS 2007, Excel 2007, EpiInfo Version 3.5.3_ 2011 and SPSS 16 were used for the data collection and analysis. 


\section{Patients}

Inclusion criteria: Patients were from ENT department of Aristide Le Dantec and Fann Hospitals. This work involved adult patients who underwent total laryngectomy and thyroidectomy. Exclusion criteria (or non-inclusion criteria): Patients who underwent TL without thyroidectomy. Ethical Consideration were done with informed consent.

\section{Results}

\section{Global results $(\mathrm{n}=59$ patients)}

We noted a male predominance with 58 (98, 3\%) men and one woman $(1.7 \%)$. The woman was 50 years old. For all 59 patients, the average age was 57.8 years ( 35 to 79 years) and a mode of 56 years old. An emergency tracheotomy was performed in 36 cases (72\%).

All patients underwent TL with neck dissection. The thyroid was managed as follows:

a) Total thyroidectomy in 21 cases $(35.6 \%)$.

b) Subtotal thyroidectomy in one case (1.7\%).

c) Hemi-thyroidectomy in 31 cases $(52.5 \%)$.

(NB: 5 patients received a PLT with hemi-thyroidectomy $(8.5 \%)$ and 1 patient a hemi-pharyngo-laryngectomy with a hemithyroidectomy (1.7\%).) Follow up of the clinical symptoms concerning TL with thyroidectomy was an average of 20.2 months (2 - 120 months). Tumors of the larynx were advanced (T3-T4) in 58 patients (98.3\%) according to the TNM UICC / AJC classification (Table 1). In 32 of the 59 patients (54.2\%), the histological examination of the thyroid gland was specified. Twenty-eight (28 $=87.5 \%$ ) patients had a normal histological examination and 4 $(12.5 \%)$ had invasion of the thyroid by the squamous cell carcinoma from the larynx. A histological report of the neck dissection was available in 41 patients (69\%); 22 of them (53.7\%) had nodal metastases $(\mathrm{N}+)$. Twenty-three $(23=62.9 \%)$ patients received radiotherapy. A hypothyroidism was noticed in 2 patients.

Table 1: Squamous cell carcinoma at ENT department of Academics hospitals in Dakar (2007-2011).

\begin{tabular}{|c|c|c|c|c|c|c|c|}
\hline & N0 & N1 & N2a & N2b & N2c & N3 & Total \\
\hline T1 & 0 & 0 & 0 & 0 & 0 & 0 & 0 \\
\hline T2 & 0 & 1 & 0 & 0 & 0 & 0 & 1 \\
\hline T3 & 28 & 4 & 1 & 1 & 0 & 2 & 36 \\
\hline T4 & 18 & 2 & 2 & 0 & 0 & 0 & 22 \\
\hline Total & 46 & 7 & 3 & 1 & 0 & 2 & 59 \\
\hline
\end{tabular}

\section{Observations}

Four cases of laryngeal carcinoma with invasion of the thyroid gland were collected during this period. They were all males. The average age of patients was 51.3 years ( 46 to 56 years), as evidenced by the observations summarized in Table 2. Observations are summarized in Table 2
Table 2: Laryngectomy with invasion of the thyroid gland with 4 patients.

\begin{tabular}{|c|c|c|c|c|}
\hline $\begin{array}{c}\text { Age } \\
\text { Year }\end{array}$ & Gender & TNM_pN & Treatment & $\begin{array}{c}\text { Following } \\
\text { up per day }\end{array}$ \\
\hline 53 & $\mathrm{M}$ & T4N0MX and pN- & LT+TT+RTE & $\begin{array}{c}\text { Lost sight } \\
\text { after } 305 \\
\text { days }\end{array}$ \\
\hline 56 & $\mathrm{M}$ & T4N0MX et $\mathrm{pN}-$ & LT+TT- RTE & $\begin{array}{c}\text { Dead after } \\
572 \text { days }\end{array}$ \\
\hline 46 & $\mathrm{M}$ & T3N1MX et $\mathrm{pN}-$ & LT+LIT - RTE & $\begin{array}{c}\text { Dead after } \\
367 \text { days }\end{array}$ \\
\hline 50 & $\mathrm{M}$ & T4N2AMx et $\mathrm{pN}-$ & LT+TT-RTE & $\begin{array}{c}\text { Dead after } \\
\text { 416 days }\end{array}$ \\
\hline
\end{tabular}

\section{Control according to Kaplan Meier ( $n=32$ patients)}

The 2-year survival rate was $50 \%$ for patients with laryngeal carcinoma with invasion of the thyroid and $50 \%$ for patients without invasion of the thyroid. There was a $10 \% 5$-year survival for patients with laryngeal carcinoma with invasion of the thyroid. The patients without invasion of the thyroid had 5 years and half of survival (Figure 1). The difference was not statistically significant $(\mathrm{p}=0,15)[10]$.

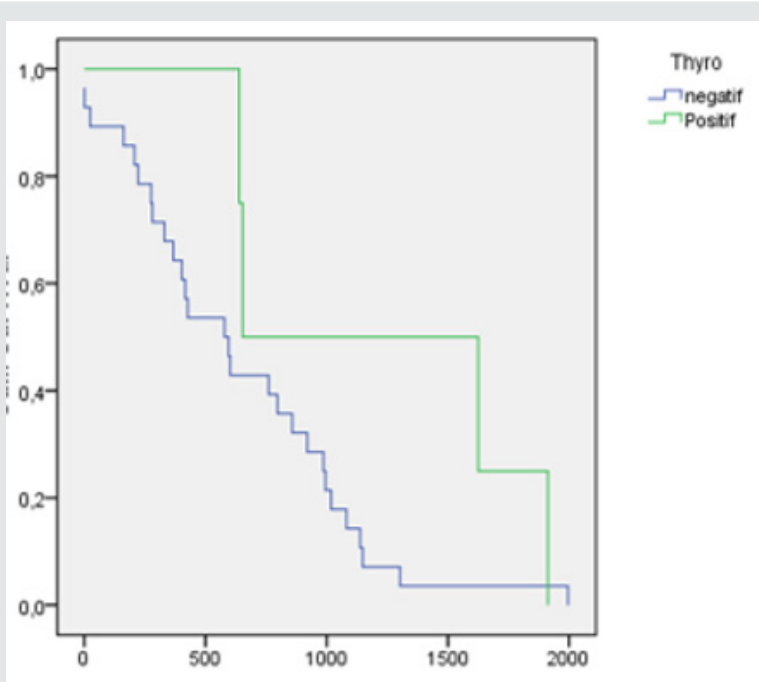

Figure 1: TL with invasion of the thyroid (thyro positive) vs TL without any invasion of the thyroid (thyro negative): $p=0,15$.

\section{Discussion}

\section{Epidemiology}

Age: In international literature, the age of patients with laryngeal cancer differs from one study to another and ranges from 42 to 83 years old and with an average between 60 and 65 years. In our study, the mean age of patients is consistent with the results found in these series but is still relatively young. According to Elliot [10] it is 61.05; according to Gaillardin [1] it is 61; and according to KIM [11] it is 63.2 , while our study patients had an average age of 57.81 . 
Gender: There is a visible male predominance in our study as well as for many other studies. In our series, $98.3 \%$ of patients were male and $1.7 \%$ was female. According to Dadas [12], the corresponding rates were $97.80 \%$ and $2.19 \%$; according to ELLIOTT [10] 85.71\% and 14.28\%; according to Gaillardin [1] 96.55\% and $3.44 \%$, and finally to Kim [11] of $96.42 \%$ and $3.57 \%$.

\section{Diagnosis}

Clinical data: Most of the studies do not address any clinical data considering laryngeal cancer. In our cases, all patients $(n=59$ $=100 \%$ ) had dysphonia, and 50 had stridor requiring emergency tracheostomy in 36 cases (72\%) [12].

Special investigations: According to the Gaillarin studies et al. [1], tomodensitometrical criteria used were the (partial or complete) destruction of the laryngeal cartilages (thyroid and cricoid) and cervical adenopathy. The results are shown in Figure 2 below. In this study, just over $40 \%$ of patients, with a CT scan showing destruction of the cricoid cartilage had histological invasion of the thyroid. However, more than a third of the invasions of the thyroid were not suspected on preoperative TDM. But Mendelson et al. [13], in their meta-analysis, showed that there is no significant link between the TDM destruction of the cricoid cartilage and the histological invasion of the thyroid. In our cases, only 10 patients (16.9\%) underwent a neck CT scan, of which 4 had destruction of the thyroid cartilage. Four others had destruction of the cricoid cartilage and 4 had neck adenopathy. None of these results were of value as the 4 patients with invasion of the thyroid gland did not undergo TDM.

\begin{tabular}{|c|c|c|c|c|c|}
\hline $\begin{array}{l}\text { Évaluation TDM } \\
\text { préopératoire }\end{array}$ & $\begin{array}{l}\text { Envahissement de la } \\
\text { thyroïde }\end{array}$ & $\begin{array}{l}\text { Pas d'envahissement } \\
\text { de la thyroïde }\end{array}$ & p & $\mathrm{Se}(\%)$ & Sp (\%) \\
\hline $\begin{array}{l}\text { Destruction cartilage } \\
\text { thyroïde }\end{array}$ & $\begin{array}{l}5 \text { ( } 4 \text { cancers larynx, } \\
1 \text { SP) }\end{array}$ & $\begin{array}{l}18 \text { ( } 14 \text { cancers larynx, } \\
4 \text { SP) }\end{array}$ & 0,12 & 45 & 76 \\
\hline $\begin{array}{l}\text { Destruction cartilage } \\
\text { cricoïde }\end{array}$ & $\begin{array}{l}5 \text { ( } 4 \text { cancers larynx, } \\
1 \text { SP) }\end{array}$ & $\begin{array}{l}7 \text { (6 cancers larynx, } \\
1 \text { SP) }\end{array}$ & 0,001 & 45 & 90 \\
\hline $\begin{array}{l}\text { Adénopathies cervicales } \\
\text { métastatiques (tout } \\
\text { N1, N2, N3) }\end{array}$ & $\begin{array}{l}8 \text { ( } 3 \text { cancers larynx, } \\
5 \text { SP) }\end{array}$ & $\begin{array}{l}35 \text { ( } 16 \text { cancers larynx, } \\
19 \text { SP) }\end{array}$ & 0,11 & 72 & 54 \\
\hline
\end{tabular}

Figure 2: CT scan criteria studied [1].

MRI examination remains a second-line examination, mainly because the sequences of tissue characterization are often artifactual due to swallowing movements [14]. Endoscopy is the key consideration; all reports show a strong link between subglottic extension (SGE) of the tumor and invasion of the thyroid gland. This SGE was measured using the tip of the scope [1]. Four approaches emerge from our reading: Biel et al. performed TT or hemi-thyroidectomy for cancers of the larynx with SGE of more or equal to $10 \mathrm{~mm}-1$. Dada et al. [12] perform a hemithyroidectomy for cancers of the larynx with SGE that exceeds or equals $10 \mathrm{~mm}$ and in cases of invasion of the thyroid cartilage on CT scan. Sparano et al. perform a hemithyroidectomy for laryngeal cancers if SGE exceeds $15 \mathrm{~mm}$, the vocal fold is involved, with anterior commissure tumor, laryngeal ventricle tumor, cricothyroid membrane tumor and extension of tumor into the thyroid cartilage. Kim et al. [11] perform a prophylactic hemi-thyroidectomy for any subglottic tumor extension. In our series, all four patients with an invasion of the thyroid gland had an invasion of the sub glottis.

TNM Classification: All patients with invasion of the thyroid gland in laryngeal cancers were classified as T3 of T4 according to the UICC classification (2002 version) in our series as well as in the international literature, presented in the Table 3 below. Based on our study, twenty-eight $(28=87.5 \%)$ patients had normal histological examination and $4(12.5 \%)$ had an invasion of the thyroid gland by squamous cell carcinoma starting in the larynx. Our prevalence figure of tumor invasion of the thyroid $(12.5 \%)$ is almost at the same level as those in the literature. Elliott [10] reported a prevalence of invasion of $8.5 \%$, Gaillardin [1] 12.6\%, Hernandez [15] 12\%, Kim [11] 14\%, and Sparano [16] 23\%.

Table 3: TNM classification of patients with invasion of the thyroid gland by series.

\begin{tabular}{|c|c|}
\hline Serie & TNM Classification \\
\hline \multirow[t]{4}{*}{ Elliott [10] } & 3 patients with invasion of the thyroid : \\
\hline & $-\mathrm{T} 4 \mathrm{~N} 2 \mathrm{cM} 0$ \\
\hline & $-\mathrm{T} 4 \mathrm{~N} 2 \mathrm{cM} 0$ \\
\hline & -T4N0M1 \\
\hline \multirow[t]{3}{*}{ Gaillardin [1] } & 11 patients with invasion of the thyroid : \\
\hline & 6 with cancer of larynx, they were classified T4 \\
\hline & 5 with cancer of the hypopharynx, 2 T4 and 3 T3 \\
\hline \multirow[t]{2}{*}{$\operatorname{Kim}[11]$} & 4 patients with invasion of the thyroid: \\
\hline & They were all classified T4 \\
\hline \multirow[t]{5}{*}{ Our study } & 04 patients with invasion of the thyroid : \\
\hline & $-\mathrm{T} 4 \mathrm{~N} 0 \mathrm{Mx}$ \\
\hline & $-\mathrm{T} 4 \mathrm{~N} 0 \mathrm{Mx}$ \\
\hline & $-\mathrm{T} 3 \mathrm{~N} 1 \mathrm{Mx}$ \\
\hline & $-\mathrm{T} 4 \mathrm{~N} 2 \mathrm{aMx}$ \\
\hline
\end{tabular}

\section{Treatment}

Lymphadenectomy: Lymph node invasion was present in more than $50 \%$ of our patients. This aspect has not drawn the attention of some authors [1]. 


\section{Surgery:}

a) According to Gaillardin [1] in 87 studied cases, a TL was associated with TT in 35 cases (40.22\%) and with a hemithyroidectomy in 17 cases (19.54\%); PLT was associated with a TT in 10 cases $(11.49 \%)$ and with a hemi-thyroidectomy in 25 cases $(28.73 \%)$.

b) According to Elliott [10] in 35 studied cases, TL was performed in 22 cases (62.85\%), and PLT was performed in the 13 remaining cases $(37.15 \%)$. TT was performed in 32 cases $(91.42 \%)$ and a hemi-thyroidectomy in 3 cases $(8.57 \%)$.

c) In our study of 59 cases, TL was associated with TT in 21 cases $(35.59 \%)$, with hemi-thyroidectomy in 31 cases $(52.54 \%)$ and with subtotal thyroidectomy in one case (1 69\%); PLT was associated with an hemithyroidectomy in 5 cases $(8.47 \%)$; and hemipharyngolaryngectomy with a hemithyroidectomy in 1 case $(1.69 \%)$. We note that in our study we did more hemithyroidectomies compared to the international literature.

Radiotherapy: In our case study, only 23 patients (62.85\%) received radiotherapy. In the international literature cases, radiotherapy is systematic for all patients.

Hormonal therapy: Thyroidectomy endocrine consequences should be highlighted in these patients who used to receive complementary radiotherapy that compound endocrine complications. Indeed, during the postoperative period, hypothyroidism was found in $45 \%$ of patients treated with surgery and radiotherapy and 70\% after thyroidectomy and complementary radiotherapy [12]. In our study 2 irradiated patients had hypothyroidism.

Survival Prognosis: As to Kim [11] and Elliot [10], the prognosis was better for patients without any invasion of the thyroid; however, the difference was not statistically significant. The 5-year survival was $25 \%$ from the KIM study [11] compared to ours $(10 \%)$. This poor performance is certainly caused by the delay in consultation but mainly by the lack of a technical platform in Senegal.

\section{Conclusion}

Invasion of the thyroid gland in advanced laryngeal tumours is proven and his prevalence in our study is $12.5 \%$. Invasion of sub glottis area and anterior extension of laryngeal cancers are the main directions for thyroidectomy. In our study, we recommend a reduction of TT or a hemi-thyroidectomy during laryngectomy because of the complications (operative time, thyroidectomy morbidity and mortality, potential endocrine complications...).

\section{Key point}

a) $12.5 \%$ of the patients of our series had an invasion of the thyroid gland by squamous cell carcinoma starting in the larynx. b) In our study, as in those in the literature, a TT or a hemithyroidectomy during laryngectomy was performed in more than $87 \%$ of cases. This is unacceptable in view of the complications (operative time, thyroidectomy morbidity and mortality, potential endocrine complications...).

\section{References}

1. Gaillardin L, Beutter P, Cottier JP (2012) Invasion of the thyroid gland during pharyngolaryngeal squamous: prevalence, predictive endoscopic and tomodensitometric factors Ann. Fr d ORL and cervicofacial Pathology 129: 5-9.

2. Diallo BK, Diouf R, Tall A (2000) The partial laryngectomy at the Centre Hospitalier Universitaire of Dakar. Dakar Médical 45(1): 42-44.

3. Diallo BK, Lacher Fougere S, Baltazart B (2008) Results of the mixture of two products from the sea for the cicatrization disorders in cervicofacial cancer. Rev Laryngol Otol Rhinol 129(5): 289-292.

4. Diallo BK, Loum B, Tall A (2004) Preliminary study of the laryngeal cancer on a senegalese woman. Bull Med Owendo 22: 5-7.

5. Diallo BK, Tchambe TT, Diouf R, Diop EM (2004) Trachéotomy et Laryngectomy at CHU of Dakar Revue africaine d'ORL et de Chirurgie Cervico faciale 1(2): 36-39.

6. Diallo BK, Toure S, Sankale AA (2005) Le lambeau de pectoralis major: Anatomic bases and cervicofacial carcinology indications Dakar médical 50(3): 142-145.

7. Diop EM, Diouf R, Ndiaye I (2000) Maladies Tropicales Oto-rhinolaryngologiques EMC 20(925): 10-16.

8. Diop EM, Toure P, Diop LS (1984) Cervicofacial cancers: ORL clinical experiences at CHU of Dakar Médecine d'Afrique noire 31: 541-549.

9. Diouf R, Diallo BK, Tall A (1999) Laryngeal Cancers: which therapeutical method are used in Senegal. Dakar Médical 44(2): 70-73.

10. Elliott MS, Odell EW, Tysome JR (2010) Role of thyroidectomy in advanced laryngeal and pharyngolaryngeal carcinoma ORL Head and neck surgery 142(6): 851-855.

11. Kim JW, Han GS, Byun SS (2008) Management of thyroid gland invasion in laryngopharyngeal cancer Auris Nasus Larynx 35(2): 209-212.

12. Dadas B, Uslu B, Kakir B (2001) Intraoperative management of thyroid gland in laryngeal cancer surgery. J Otolaryngol 30(3): 179-183.

13. Mendelson AA, AL Khatib TA, Julien M (2009) Thyroid gland management in total laryngectomy: Meta-analysis and surgical recommendations. ORL Head and neck Surg 140(3): 298-305.

14. Chevalier D, Dubrulle FET, Villette B (2001) Endoscopic descriptive anatomy and laryngeal radiology. EMC oto-rhino-laryngologie 20(630): $10-13$

15. Hernandez JF, Minauro MG, Hernandez H (2005) Thyroidectomy associated with laryngectomy in laryngeal cáncer treatment. Is it routinely necessary Cir Cir 73(1): 3-6.

16. Sparano A, Chernock R, Laccourreye 0 (2005) Predictors of thyroid gland invasion in glottic squamous cell carcinoma. Laryngoscope 115(7): 1247-1250 
(C) (i) This work is licensed under Creative

To Submit Your Article Click Here: Submit Article

DOI: $10.32474 /$ SJ0.2020.03.000172

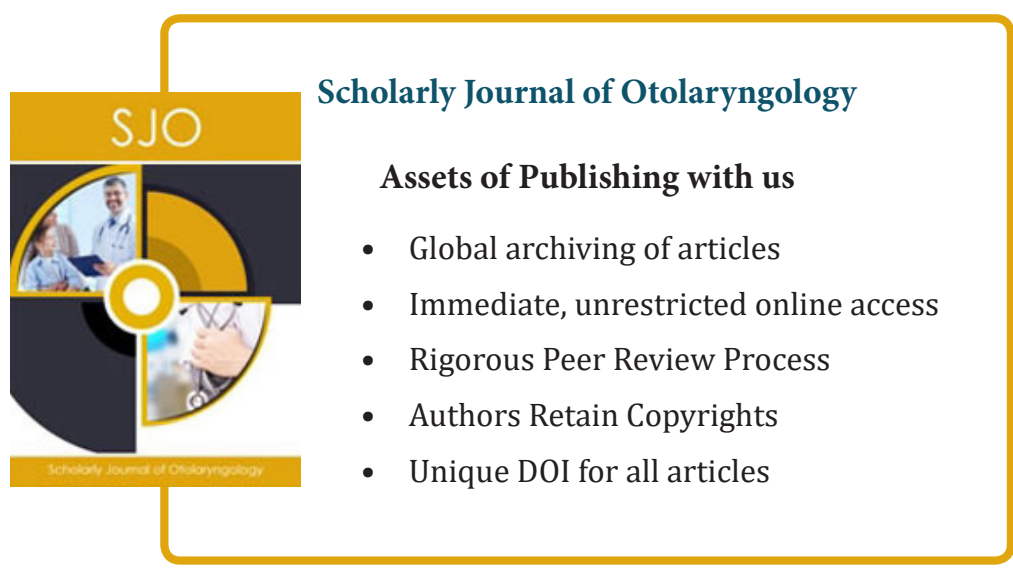

